\title{
Medical and allied health service use during acute and chronic post-injury periods in whiplash injured individuals
}

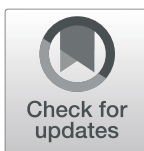

\author{
Carrie Ritchie $^{1 *}$, Ashley Smith ${ }^{2,3}$ and Michele Sterling ${ }^{1,4}$
}

\begin{abstract}
Background: Individuals with whiplash associated disorder (WAD) frequently experience neck pain in addition to other physical, psychological and social symptoms. Consequently, treatment is sought from a variety of health professionals. The limited data available about health services use in this population are conflicting. This study aimed to characterise health service use in individuals with WAD from a motor vehicle crash.
\end{abstract}

Methods: Medical (general practitioner (GP), medical specialist, emergency services (ED), radiology - $x$-ray, computed tomography, magnetic resonance imaging, ultrasound) and allied health service (physiotherapy, chiropractor, psychologist, osteopath, occupational therapy) use during acute ( $<12$ weeks) and chronic (12 weeks to 2 years) post-injury periods were analysed in adults claiming compensation for WAD in the no-fault jurisdiction of Victoria, Australia $(n=37,315)$.

Results: Most WAD claimants had an acute post-injury health service payment $(95 \%, n=35,348)$, and approximately onethird $(29 \%, n=10,871)$ had a chronic post-injury health service payment. During an acute post-injury period, the most frequently compensated services were for: ED (82\% of acute claimants), radiology (56\%), and medical specialist (38\%). Whereas, physiotherapy (64.4\% of chronic claimants), GP (48.1\%), and radiology (34.6\%) were the most frequently paid services during the chronic period. Females received significantly more payments from physiotherapists $(F=23.4 \%, M=$ $18 \%, z=-11.3, p<.001, r=0.13$ ), chiropractors $(F=7.4 \%, M=5.6 \%, z=-6.3, p<.001, r=0.13)$, and psychologists $(F=4.2 \%$, $M=2.8 \%, z=-6.7, p<.001, r=0.18)$; whereas, males received significantly more medical services payments from medical specialists ( $F=41.8 \%, M=43.8 \%, z=-3.7, p<.001, r=0.03), E D(F=74.0 \%, M=76.3 \%, z=-4.9, p<.001, r=0.03)$ and radiology $(F=58.3 \%, M=60.1 \%, z=-3.4, p<.001, r=0.02)$.

Conclusions: Individuals with WAD claimed for a range of health services. Radiology imaging use during the acute postinjury period, and physiotherapy and chiropractor service use during the chronic post-injury period appeared concordant with current WAD management guidelines. Conversely, low physiotherapy and chiropractic use during an acute postinjury period, and high radiology and medical specialists use during the chronic post-injury period appeared discordant with current guidelines. Strategies are needed to help inform medical health professionals of the current guidelines to promote early access to health professionals likely to provide an active approach to treatment, and to address unnecessary referral to radiology and medical specialists in individuals with on-going WAD.

Keywords: Whiplash injuries, Neck pain, Radiology, Physical therapist, Health services, Acute pain, Chronic pain, Medicine, General practitioners

\footnotetext{
* Correspondence: c.ritchie@uq.edu.au

${ }^{1}$ Recover Injury Research Centre, The University of Queensland, Brisbane, Queensland, Australia

Full list of author information is available at the end of the article
}

(c) The Author(s). 2020 Open Access This article is licensed under a Creative Commons Attribution 4.0 International License, which permits use, sharing, adaptation, distribution and reproduction in any medium or format, as long as you give appropriate credit to the original author(s) and the source, provide a link to the Creative Commons licence, and indicate if changes were made. The images or other third party material in this article are included in the article's Creative Commons licence, unless indicated otherwise in a credit line to the material. If material is not included in the article's Creative Commons licence and your intended use is not permitted by statutory regulation or exceeds the permitted use, you will need to obtain permission directly from the copyright holder. To view a copy of this licence, visit http://creativecommons.org/licenses/by/4.0/ The Creative Commons Public Domain Dedication waiver (http://creativecommons.org/publicdomain/zero/1.0/) applies to the data made available in this article, unless otherwise stated in a credit line to the data. 


\section{Background}

Whiplash-associated disorder (WAD) is the term used to describe an array of symptoms incurred from an acceleration/deceleration injury to the neck, usually following a motor vehicle crash (MVC). WAD is the most common and costly of all survivable MVC injuries [1]. Approximately $50 \%$ of individuals with WAD fully recovery while the remaining $50 \%$ continue to experience some level of on-going pain or disability $[2,3]$. Although neck pain is the most frequent symptom, it is common for individuals with WAD to experience other physical, psychological, and social symptoms $[4,5]$. Consequently, injured individuals may seek treatment from a variety of health professionals for pain as well as other symptoms.

Clinical guidelines for WAD management focus on treatment during the acute post-injury period since most recovery, if it occurs, takes place in the initial 3 months postinjury with little improvement after this time point $[2,6]$. Acute clinical WAD management guidelines recommend that health service providers provide: reassurance; advice to stay active and return to usual activities as soon as possible; and, if needed, simple analgesic and non-steroidal antiinflammatory medicines. In addition, these guidelines recommend against passive treatments such as immobilisation with a cervical collar, surgery or pharmacological injections [7-10]. The limited clinical guidelines for individuals with on-going WAD (e.g. > 3 months post-injury) also recommend exercise and activity management, and if psychological symptoms are present, the possible addition of behavioural and psychological strategies [9, 10]. To our knowledge, there are no data available that delineate acute from chronic health service use by individuals with WAD.

Timing and volume of health service use after an acute whiplash injury appear to affect health outcomes, healthcare utilisaton and costs [11-13]. Individuals with WAD who waited more than 28 days after their injury to consult a physiotherapist reported greater healthcare use compared with those who consulted a physiotherapist within 28 days of their injury [14]. Additionally, individuals with neck pain who waited $>90$ days to consult a physiotherapist accessed more guideline discordant health services (e.g., spinal injections) compared with individuals who consulted a physiotherapist within 14 days of a new eipsode of neck pain [11]. On the other hand, overtreatment by healthcare providers in the first 3 months following a whiplash injury has been shown to slow recovery $[12,13]$.

The limited data available about the types of health services used by this population are conflicting. Survey results showed that over one-half of emergency and primary health medical practitioners indicated that they would refer patients with WAD to physiotherapists $[15,16]$, orthopaedic specialists [16], and psychologists [16]. However, audits of general practitioner (GP) management of individuals with WAD in Australia [17] and insurance claimant data in Canada [12] found that less than onequarter of individuals were referred to physiotherapists and medical specialists. There appears to be no data available about referral of individuals with WAD to psychologists. Although optimal management of WAD is not yet known, to ensure compliance with current WAD management guidelines, a better understanding of current health service utilization during acute and chronic post-injury periods is needed. This study aimed to characterise health service use during acute and chronic post-injury periods in individuals with WAD from a MVC. In addition, we aimed to identify factors predictive of: a) likely recovery (health care service utilization only during acute phase); and b) high health care service utilization (highest quartile of overall health service use).

\section{Methods}

Participants were not recruited to this study directly. Deidentified data from the Compensation Research Database (CRD) were provided by the Institute for Safety, Compensation and Recovery Research in Victoria, Australia, an initiative funded by the Transport Accident Commission (TAC) (https://www.tac.vic.gov.au/). The TAC is a government organisation within the state of Victoria, the second most populous state in Australia. The TAC pays for the treatment and benefits of all individuals (i.e. vehicle occupants, cyclists and pedestrians) involved in an accident caused by a motorised vehicle registered in the state of Victoria. The injured person (or representative) generally has 12 months from date of injury to initiate a claim for compensation. The existent no-fault compensation system within Victoria means that injury-related medical and rehabilitation costs are compensated whether or not the claimant is considered to be at fault for the accident. However, most medical and allied health treatment costs incur a medical excess. A claimant must pay the medical excess before being eligible for reimbursement from the TAC. The medical excess amount varied during the study period from AU\$450 (in 2000) to AU\$599 (in 2013). For this specific study, data were analysed for medical and allied health service claims only. Pharmaceutical claim payments have been analysed previously [18].

\section{Participants}

Data were provided for all claimants with a transport related injury date between 1 January 2000 and 31 December 2013 who met the following inclusion criteria: $(1) \geq$ 18 years; (2) most serious injury coded by the TAC was a whiplash injury (i.e. cervical spine strain with or without minor physical injuries to other parts of the body, e.g. contusions/laceration), (3) were not admitted to hospital as a result of their transport related injury; and (4) 
received a claim payment for at least one health service (i.e. medical or allied health service).

For each individual, data were extracted for all medical (e.g. emergency services, general practitioners, medical specialists, radiology), and allied health service (e.g. physiotherapy, chiropractic, osteopathy, psychology, occupational therapy) claims paid during the life of their claim or up to a maximum of 2 years post injury. Human research ethics approval was granted from The University of Queensland (\#2017001361/2016/112).

\section{Data}

Demographic data included: sex; age at the time of MVC; area of residence (major cities, inner regional, outer regional, remote or very remote) [19]; year of MVC; and whether or not the claimant had lodged a common law claim. A common law claim is a court action commenced within 6 years of the date of injury that requires the claimant to have an injury deemed to be 'serious' and to be able to show that another person was at fault. An acute claim payment was defined as a health service provided within 12 weeks of the MVC, and a chronic claim payment was defined as a health service provided between 12 weeks and 2 years post-MVC.

Paid health service claims were grouped into one of nine categories that comprised allied health services from: (1) physiotherapists, (2) chiropractors, (3) osteopaths, (4) psychologists, and (5) occupational therapists (OT); and medical services from: (6) general practitioners (GP), (7) medical specialists, (8) emergency services, and (9) radiology services. Radiology services were further specified as: plain radiograph (x-ray), computed tomography scans $(\mathrm{CT})$, magnetic resonance imaging scans (MRI), and ultrasound.

\section{Analyses}

Specific health service and imaging use were described by the demographic factors: age, sex, area of residence, year of MVC, and lodgement of common-law claim for both prevalence (e.g. the number of health service group claimants divided by total WAD claimants) and as an aggregate (e.g. the number of specific health service sessions among users). Health service use was also described for postinjury claim phases (e.g., acute or chronic post-injury phase). All variables were non-normally distributed, hence non-parametric statistics were used to compare demographic data between groups. Logistic regression was used to determine predictive factors associated with two health service use profiles: 1 . likely recovery, e.g. only acute postinjury health service claims; and 2. high health care service utilization, e.g. the highest quartile of overall health service claims. The demographic factors outlined above were the possible predictive factors.

\section{Results}

\section{Health service use}

Between 1 January, 2000 and 31 December, 2013, 37,315 individuals were paid a compensation claim for a health service following a whiplash injury through the TAC in Victoria, Australia. Approximately two-thirds of claimants were female, and the majority lived in a major city (Table 1). One-quarter of claimants were aged 18-24 years and claims incidence decreased with increasing age. Only $4 \%$ of claimants lodged a common law claim (Table 1 ). Three in four claimants received a compensation payment for emergency services and three in five for a radiology claim (Table 1). Of the health professional service categories, medical specialists were seen by the largest number of claimants followed by GPs (Table 1). Only one in five claimants received compensation payment for physiotherapy services and less than one in ten for chiropractic service. There were no differences in the proportions of males and females who claimed for health services from GPs. However, compared with males, females were significantly more likely to receive a compensation payment for all allied health services (e.g. physiotherapists, chiropractors, osteopaths, psychologists, and OT); whereas, males were more likely receive a compensation payment for medical services from medical specialists, emergency services and radiology (Table 1). Comparison of health service use by age group revealed that: claimants in the youngest age category (18-24 years) were less likely to receive payment for all services except emergency services; claimants aged $45-64$ years were more likely than younger and older groups to receive payment for physiotherapy, GP and medical specialist services; and claimants in the oldest age group ( $\geq 65$ years) were more likely than younger age groups to receive payment for radiology (Table 1). Health service use by area of residence showed that claimants from major cities were significantly more likely to receive payment for medical specialist services compared with regional and remote areas, whereas claimants from regional and remote areas were more likely to receive payment for GP services compared with claimants from major cities (Table 1). In addition, claimants from major cities were almost twice as likely to receive payment for physiotherapy and psychology services compared with claimants from regional areas. Individuals who lodged a common law claim were significantly more likely to receive a compensation claim for all health services except emergency services compared with claimants who did not lodge a common law claim (Table 1).

Of the claimants with radiological imaging claim payments, most (87\%) had a plain radiograph payment, onequarter had a CT scan, and one in ten had a MRI (Table 2). Compared with females, males were more likely to receive payment for plain radiographs and CT scans. The youngest aged claimants (18-24 years) were significantly more likely 


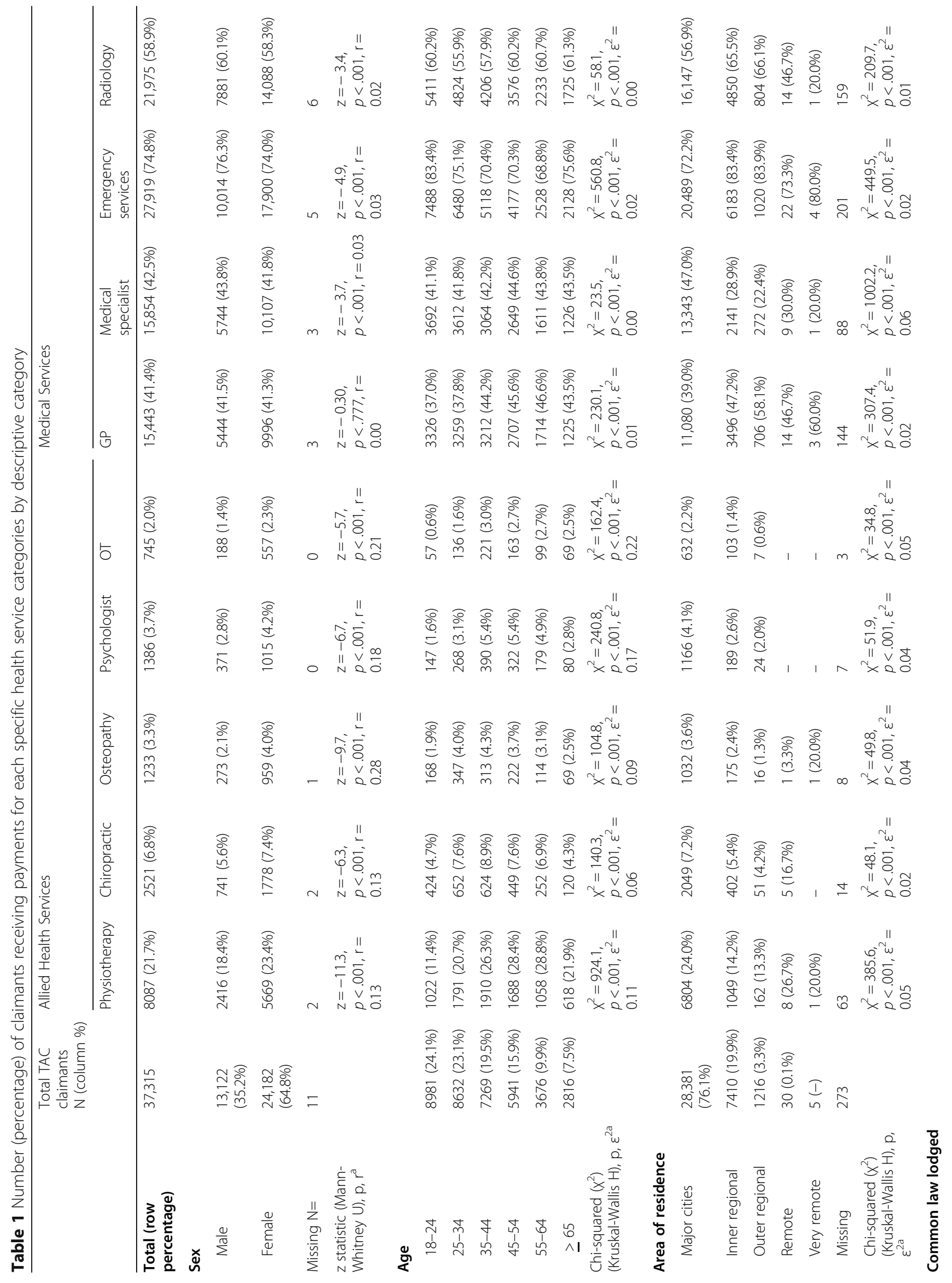




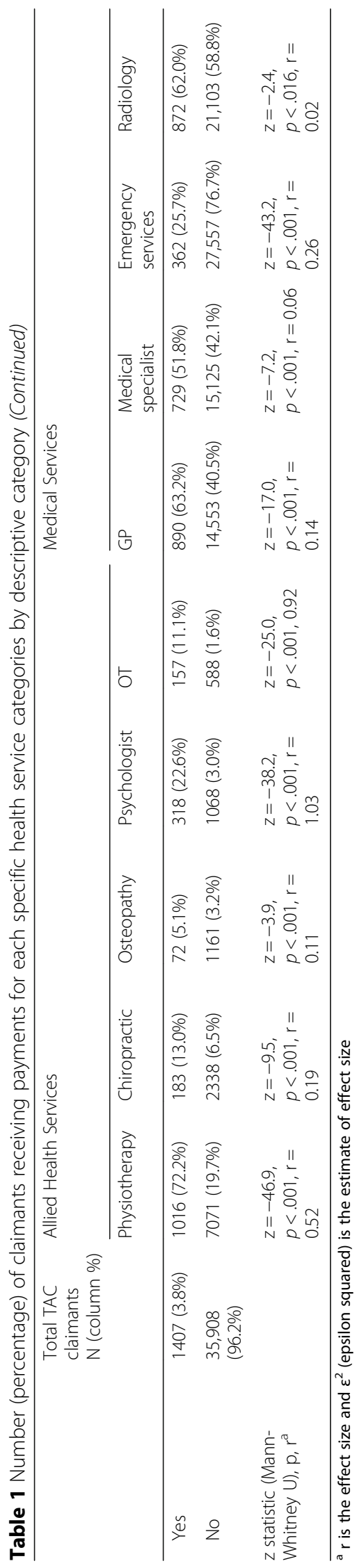


Table 2 Number (row percentage) of radiology claimants receiving specific radiology type claims within each descriptive category

\begin{tabular}{|c|c|c|c|c|c|}
\hline & $\mathrm{n}$ & Plain radiograph (x-ray) & MRI & $C T$ & Ultrasound \\
\hline Total & $\begin{array}{l}21 \\
975\end{array}$ & $19,183(87.3 \%)$ & $2236(10.2 \%)$ & $5511(25.1 \%)$ & $1427(6.5 \%)$ \\
\hline \multicolumn{6}{|l|}{ Sex } \\
\hline Male & 7881 & $6888(87.4 \%)$ & $819(10.4 \%)$ & $2158(27.4 \%)$ & $478(6.1 \%)$ \\
\hline Female & $\begin{array}{l}14 \\
088\end{array}$ & $12,291(87.2 \%)$ & $1416(10.0 \%)$ & $3350(23.8 \%)$ & $948(6.7 \%)$ \\
\hline z statistic (Mann-Whitney U), p, $\mathrm{r}^{\mathrm{a}}$ & & $\begin{array}{l}z=-3.1, p<.002, r= \\
0.02\end{array}$ & $\begin{array}{l}z=-1.5, p<.134, r= \\
0.03\end{array}$ & $z=-6.7, p<.001, r=0.09$ & $\begin{array}{l}z=-1.3, p<.182, r= \\
0.03\end{array}$ \\
\hline \multicolumn{6}{|l|}{ Age } \\
\hline $18-24$ & 5411 & $4989(92.2 \%)$ & $243(4.5 \%)$ & $1020(18.9 \%)$ & $159(2.9 \%)$ \\
\hline $25-34$ & 4824 & $4207(87.2 \%)$ & $455(9.4 \%)$ & $1132(23.5 \%)$ & $288(6.0 \%)$ \\
\hline $35-44$ & 4206 & $3542(84.2 \%)$ & $571(13.6 \%)$ & $1153(27.4 \%)$ & $308(7.3 \%)$ \\
\hline $45-54$ & 3576 & $3046(85.2 \%)$ & $550(15.4 \%)$ & $1015(28.4 \%)$ & $306(8.6 \%)$ \\
\hline $55-64$ & 2233 & $1891(84.7 \%)$ & $282(12.6 \%)$ & $662(29.6 \%)$ & $216(9.7 \%)$ \\
\hline$\geq 65$ & 1725 & $1508(87.4 \%)$ & $135(7.8 \%)$ & $529(30.7 \%)$ & $150(8.7 \%)$ \\
\hline $\begin{array}{l}\text { Chi-squared }\left(X^{2}\right) \text { (Kruskal-Wallis H), } \\
p, \varepsilon^{2 a}\end{array}$ & & $\begin{array}{l}x^{2}=112.5, p<.001, \varepsilon^{2}= \\
0.01\end{array}$ & $\begin{array}{l}x^{2}=363.0, p<.001, \varepsilon^{2}= \\
0.16\end{array}$ & $\begin{array}{l}x^{2}=200.8, p<.001, \varepsilon^{2}= \\
0.04\end{array}$ & $\begin{array}{l}x^{2}=199.7, p<.001, \varepsilon^{2}= \\
0.14\end{array}$ \\
\hline \multicolumn{6}{|l|}{ Area of residence } \\
\hline Major cities & $\begin{array}{l}16 \\
147\end{array}$ & $13,938(86.3 \%)$ & $1844(11.4 \%)$ & $3925(24.3 \%)$ & $1138(7.0 \%)$ \\
\hline Inner regional & 4850 & $4381(90.3 \%)$ & $313(6.5 \%)$ & $1304(26.9 \%)$ & $232(4.8 \%)$ \\
\hline Outer regional & 804 & 717 (89.2\%) & $52(6.5 \%)$ & $233(29.0 \%)$ & $45(5.6 \%)$ \\
\hline Remote & 14 & $11(78.6 \%)$ & $3(21.4 \%)$ & $3(21.4 \%)$ & - \\
\hline Very remote & 1 & $1(100 \%)$ & - & - & - \\
\hline $\begin{array}{l}\text { Chi-squared }\left(X^{2}\right)(\text { Kruskal-Wallis H), } \\
p, \varepsilon^{2 a}\end{array}$ & & $\begin{array}{l}x_{2}^{2}=268.9, p<.001 \\
\varepsilon^{2}=0.01\end{array}$ & $\begin{array}{l}x^{2}=61.7, p<.001 \\
\varepsilon^{2}=0.03\end{array}$ & $\begin{array}{l}x^{2}=87.1, p<.001 \\
\varepsilon^{2}=0.02\end{array}$ & $\begin{array}{l}x^{2}=13.8, p<.007 \\
\varepsilon^{2}=0.01\end{array}$ \\
\hline \multicolumn{6}{|l|}{ Common law lodged } \\
\hline Yes & 872 & $569(65.3 \%)$ & $447(51.3 \%)$ & $400(45.9 \%)$ & $196(24.5 \%)$ \\
\hline No & $\begin{array}{l}21 \\
103\end{array}$ & $18,614(88.2 \%)$ & $1789(8.5 \%)$ & $5111(24.2 \%)$ & $1231(5.8 \%)$ \\
\hline z statistic (Mann-Whitney U), p, $\mathrm{r}^{\mathrm{a}}$ & & $z=-6.7, p<.001, r=0.04$ & $\begin{array}{l}z=-41.7, p<.001, r= \\
0.88\end{array}$ & $\begin{array}{l}z=-14.8, p<.001, r= \\
0.20\end{array}$ & $\begin{array}{l}z=-20.3, p<.001, r= \\
0.53\end{array}$ \\
\hline
\end{tabular}

${ }^{a} \mathrm{r}$ is the effect size and $\varepsilon^{2}$ (epsilon squared) is the estimate of effect size

to have plain radiograph claim payments compared with older age groups, whereas, claimants aged 35-64 years were more likely than both younger and older age groups to have MRI payments, and the proportion of claimants with CT scans increased with increasing age. Compared to claimants from major cities and remote regions, claimants from regional areas were more likely to receive payments for plain radiographs and CT scans and less likely to receive payments for MRI and Ultrasound (Table 2). Three quarters $(n=16,755)$ of radiology claimants received payment for only a single type of radiology service with most single radiology payments for plain radiographs $(86 \%$ of single radiology claimants, $n=14,347)$. Of the one in five $(n=4214)$ of radiology claimants with two different types of radiology payments, most received payments for plain radiographs and CT scans $(71 \%, n=2980)$. Less than $1 \%$ of radiology claimants $(n=156)$ received payments for all four types of radiology services.

The types of health services claim payments changed over the study period. From 2000/2001 to 2012/2013, the percentages of claimants with emergency services and physiotherapy payments remained fairly stable (Fig. 1). Whereas, the percentage of claimants reduced by one-third for chiropractic and GP payments, and by $16 \%$ for radiology payments (Fig. 1). Conversely, the percentage of claimants with medical specialist services increased by $47 \%$ and increased by $35 \%$ (3.7 to $5 \%$ of year group claimants) for psychology services (Fig. 1). As shown in Fig. 2, the percentage of claimants with plain radiograph payments decreased by one-third from the beginning to the end of the study 


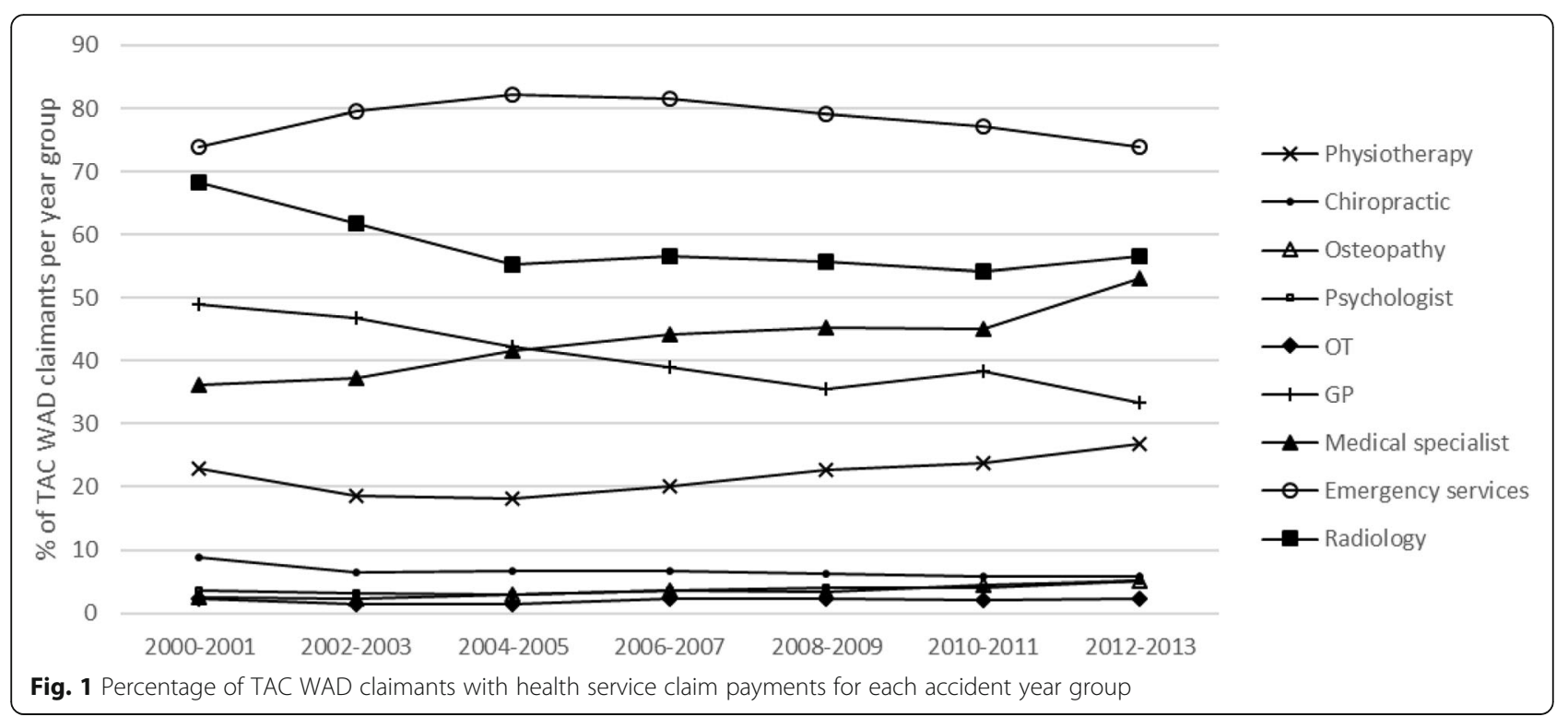

period, whereas, the percentage of claimants with MRI payments doubled and the percentage of claimants with CT scan payments increased by $130 \%$.

\section{Post-injury period}

Almost all TAC WAD claimants received a payment for an acute post-injury health service $(95 \%, n=35,348)$ and approximately one-third $(29 \%, n=10,871)$ received a payment for a chronic post-injury health service (Table 3). During the acute post-injury period, over four in five acute post-injury claimants had an emergency services payment, over one in two had a radiology payment, and over one in three had a payment for a medical specialist or GP (Table 3). During the chronic postinjury period: over three of five claimants had a physiotherapy payment, almost one-half a GP payment, one in five a chiropractor payment, and just over one in ten had a psychology payment. In addition, over one in three continued to have payments for medical specialist or radiology services. At both post-injury periods, more females than males claimed for all allied health services (except $\mathrm{OT}$ at acute post-injury). Whereas, during the chronic recovery period, a greater proportion of males compared to females had medical payments for GP, medical specialist and radiology services. For females and males, the median number of payments per claimant were highest for physiotherapy and chiropractic services during both acute and chronic post-injury periods (Table 3 ).

The types of radiological imaging claimed differed between the acute and chronic post-injury periods. During the acute post-injury period, plain radiographs were claimed by most female and male radiology claimants,

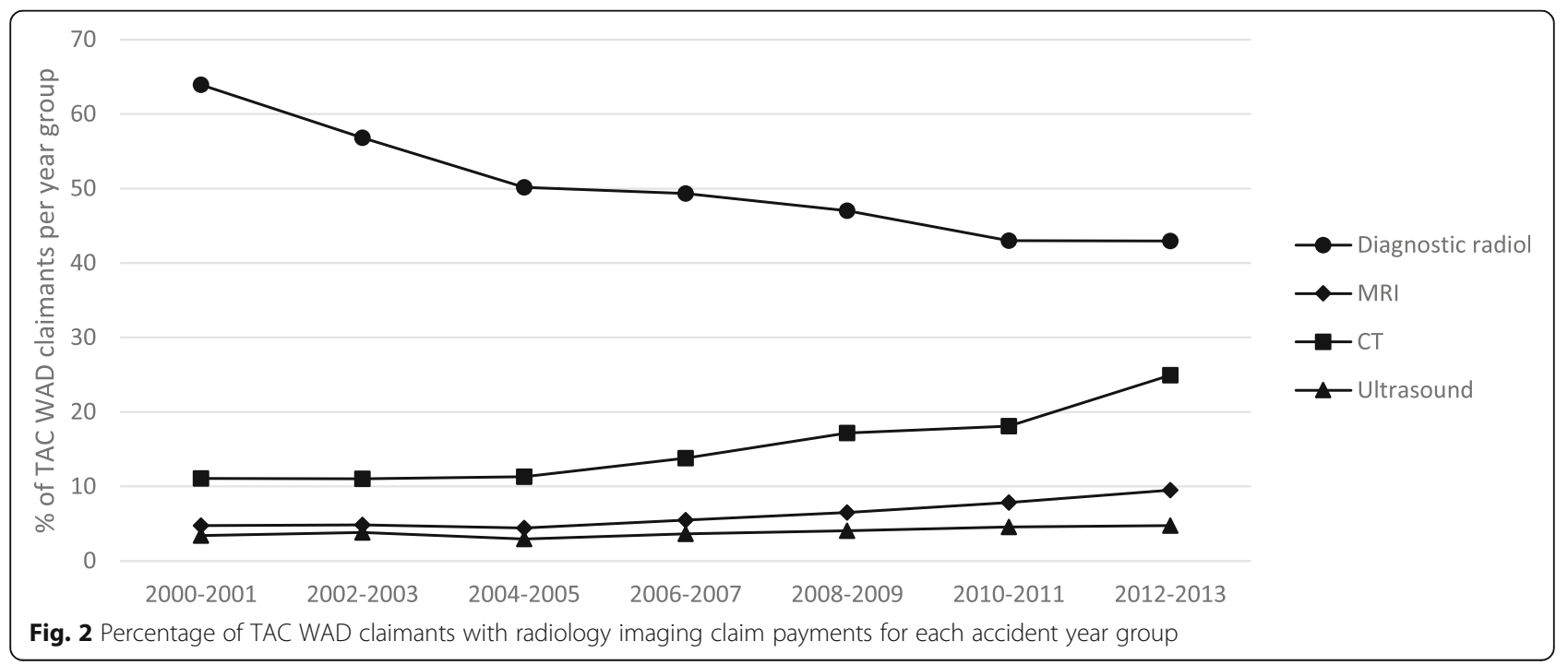


Table 3 Data are presented for total, acute and chronic claims and include total number of service group claimants, and details relating to the number of service claim payments ([interquartile range]) per claimant within each service group, and for female and male claimants

\begin{tabular}{|c|c|c|c|c|c|c|c|c|c|c|c|c|}
\hline & \multicolumn{6}{|c|}{ Acute Post-injury Period } & \multicolumn{6}{|c|}{ Chronic Post-injury Period } \\
\hline & Total & & Female & & Male & & Total & & Female & & Male & \\
\hline & $\begin{array}{l}\text { Claimants } \\
\mathrm{n} \\
\text { (column } \\
\%)\end{array}$ & $\begin{array}{l}\text { Median } \\
\text { claims n } \\
{[\mathrm{IQR}]}\end{array}$ & $\begin{array}{l}\text { Claimants } \\
\mathrm{n} \\
\text { (column } \\
\% \text { ) }\end{array}$ & $\begin{array}{l}\text { Median } \\
\text { claims n } \\
{[\mathrm{IQR}]}\end{array}$ & $\begin{array}{l}\text { Claimants } \\
\mathrm{n} \\
\text { (column } \\
\%)\end{array}$ & $\begin{array}{l}\text { Median } \\
\text { claims n } \\
{[\mathrm{IQR}]}\end{array}$ & $\begin{array}{l}\text { Claimants } \\
\mathrm{n} \\
\text { (column } \\
\% \text { ) }\end{array}$ & $\begin{array}{l}\text { Median } \\
\text { claims n } \\
{[\mathrm{IQR}]}\end{array}$ & $\begin{array}{l}\text { Claimants } \\
\mathrm{n} \\
\text { (column } \\
\%)\end{array}$ & $\begin{array}{l}\text { Median } \\
\text { claims n } \\
{[\mathrm{IQR}]}\end{array}$ & $\begin{array}{l}\text { Claimants } \\
\mathrm{n} \\
\text { (column } \\
\% \text { ) }\end{array}$ & $\begin{array}{l}\text { Median } \\
\text { claims n } \\
\text { [IQR] }\end{array}$ \\
\hline Total & 35,348 & $4[3,6]$ & 22,910 & $4[3,6]$ & 12,427 & $4[3,5]$ & 10,871 & $24[8,55]$ & 7414 & $26[8,56]$ & 3453 & $21[7,53]$ \\
\hline Physiotherapy & $\begin{array}{l}5281 \\
(14.9 \%)\end{array}$ & $7[3,11]$ & $\begin{array}{l}3760 \\
(16.4 \%)\end{array}$ & $7[3,11]$ & $\begin{array}{l}1519 \\
(12.2 \%)\end{array}$ & $6[3,11]$ & $\begin{array}{l}7002 \\
(64.4 \%)\end{array}$ & $20[8,43]$ & $\begin{array}{l}4911 \\
(66.2 \%)\end{array}$ & $21[8,44]$ & $\begin{array}{l}2089 \\
(60.5 \%)\end{array}$ & $19[7,41]$ \\
\hline Chiropractic & $\begin{array}{l}1411 \\
(4.0 \%)\end{array}$ & $6[3,11]$ & $\begin{array}{l}1008 \\
(4.4 \%)\end{array}$ & $5[3,11]$ & $\begin{array}{l}401 \\
(3.2 \%)\end{array}$ & $6[3,11]$ & $\begin{array}{l}2229 \\
(20.5 \%)\end{array}$ & $20[7,42]$ & $\begin{array}{l}1568 \\
(21.1 \%)\end{array}$ & $20[7,41]$ & $\begin{array}{l}660 \\
(19.1 \%)\end{array}$ & $21[8,45]$ \\
\hline Osteopathy & $\begin{array}{l}594 \\
(1.7 \%)\end{array}$ & $4[2,7]$ & $\begin{array}{l}467 \\
(2.0 \%)\end{array}$ & $4[2,7]$ & $\begin{array}{l}127 \\
(1.0 \%)\end{array}$ & $4[2,6]$ & $\begin{array}{l}1090 \\
(10.0 \%)\end{array}$ & $14[5,29]$ & $\begin{array}{l}851 \\
(11.5 \%)\end{array}$ & $14[6,29]$ & $\begin{array}{l}238 \\
(6.9 \%)\end{array}$ & $12[4,29]$ \\
\hline Psychologist & $\begin{array}{l}382 \\
(1.1 \%)\end{array}$ & $3[2,5]$ & $\begin{array}{l}292 \\
(1.3 \%)\end{array}$ & $3[2,5]$ & $90(0.7 \%)$ & $2[1,3]$ & $\begin{array}{l}1301 \\
(12.0 \%)\end{array}$ & $10[4,22]$ & $\begin{array}{l}953 \\
(12.9 \%)\end{array}$ & $10[4,22]$ & $\begin{array}{l}348 \\
(10.1 \%)\end{array}$ & $9[4,21]$ \\
\hline OT & $\begin{array}{l}105 \\
(0.3 \%)\end{array}$ & $2[2,3]$ & $64(0.3 \%)$ & $2[2,4]$ & $41(0.3 \%)$ & $2[2,3]$ & $\begin{array}{l}698 \\
(6.4 \%)\end{array}$ & $5[2,18]$ & $\begin{array}{l}534 \\
(7.2 \%)\end{array}$ & $5[2,18]$ & $\begin{array}{l}164 \\
(4.7 \%)\end{array}$ & $6[2,18]$ \\
\hline GP & $\begin{array}{l}13,040 \\
(36.9 \%)\end{array}$ & $1[1,1]$ & $\begin{array}{l}8418 \\
(36.7 \%)\end{array}$ & $1[1,2]$ & $\begin{array}{l}4619 \\
(37.2 \%)\end{array}$ & $1[1,1]$ & $\begin{array}{l}5228 \\
(48.1 \%)\end{array}$ & $5[2,14]$ & $\begin{array}{l}3485 \\
(47.0 \%)\end{array}$ & $5[2,14]$ & $\begin{array}{l}1742 \\
(50.4 \%)\end{array}$ & $6[2,15]$ \\
\hline $\begin{array}{l}\text { Medical } \\
\text { Specialist }\end{array}$ & $\begin{array}{l}13,549 \\
(38.3 \%)\end{array}$ & $1[1,1]$ & $\begin{array}{l}8624 \\
(37.6 \%)\end{array}$ & $1[1,1]$ & $\begin{array}{l}4922 \\
(39.6 \%)\end{array}$ & $1[1,1]$ & $\begin{array}{l}3349 \\
(30.8 \%)\end{array}$ & $3[1,5]$ & $\begin{array}{l}2129 \\
(28.7 \%)\end{array}$ & $3[1,5]$ & $\begin{array}{l}1219 \\
(35.3 \%)\end{array}$ & $3[1,6]$ \\
\hline $\begin{array}{l}\text { Emergency } \\
\text { Services }\end{array}$ & $\begin{array}{l}29,072 \\
(82.2 \%)\end{array}$ & $2[1,2]$ & $\begin{array}{l}17,833 \\
(77.8 \%)\end{array}$ & $2[1,2]$ & $\begin{array}{l}9975 \\
(80.3 \%)\end{array}$ & $2[1,2]$ & $\begin{array}{l}161 \\
(1.5 \%)\end{array}$ & $1[1,1]$ & $\begin{array}{l}109 \\
(1.5 \%)\end{array}$ & $1[1,1]$ & $62(1.8 \%)$ & $1[1,1]$ \\
\hline $\begin{array}{l}\text { Radiology } \\
\text { services - total }\end{array}$ & $\begin{array}{l}19,776 \\
(55.9 \%)\end{array}$ & $2[1,3]$ & $\begin{array}{l}12,648 \\
(55.2 \%)\end{array}$ & $2[1,3]$ & $\begin{array}{l}7122 \\
(57.3 \%)\end{array}$ & $2[1,3]$ & $\begin{array}{l}3758 \\
(34.6 \%)\end{array}$ & $2[1,3]$ & $\begin{array}{l}2450 \\
(33.0 \%)\end{array}$ & $2[1,3]$ & $\begin{array}{l}1307 \\
(37.9 \%)\end{array}$ & $2[1,3]$ \\
\hline
\end{tabular}

n: number

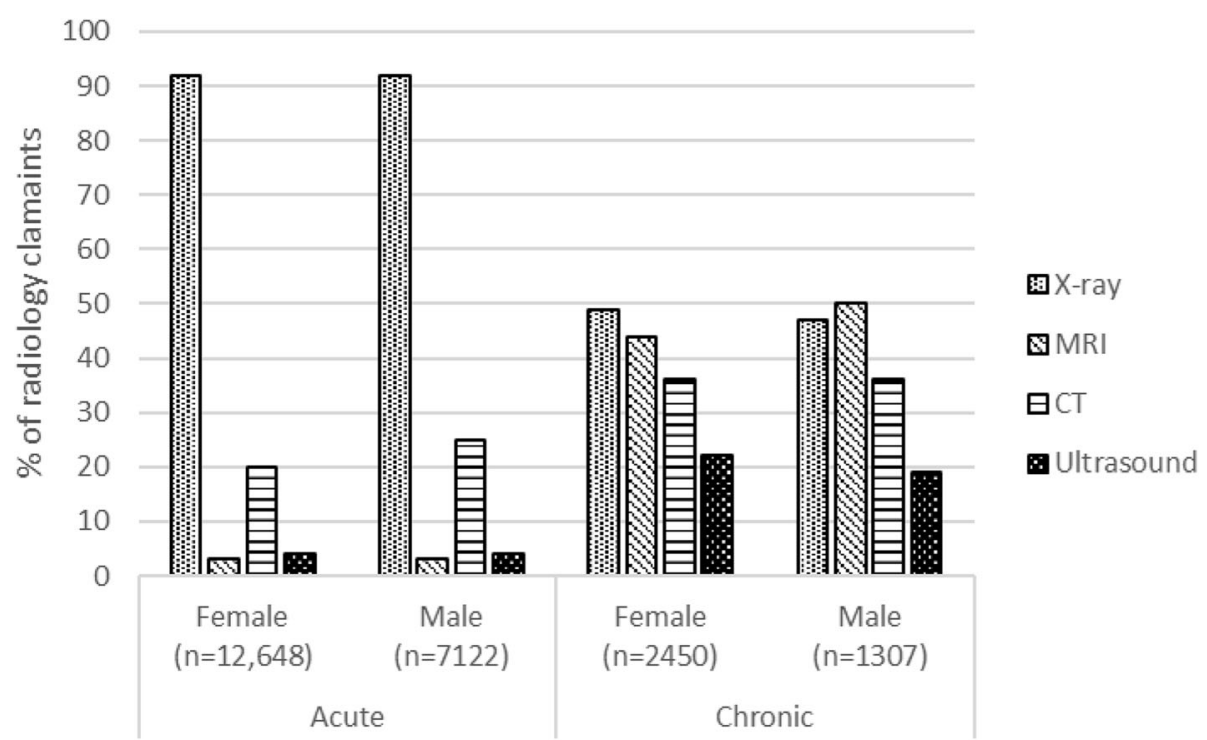

Fig. 3 Percentage of acute and chronic female and male radiology claimants receiving specific types of imaging 
although one-quarter of male and one-fifth of female acute radiology claimants had CT scans (Fig. 3). Whereas, MRI, CT scans and ultrasound were claimed much more frequently during the chronic post-injury period: $50 \%$ of male and $44 \%$ of female chronic radiology claimants had a MRI payment; and over onethird of both male and female claimants had a CT scan. Payments for plain radiographs remained high during the chronic post-injury period (Fig. 3).

\section{Health service use profiles}

It was surmised that claimants with only acute postinjury payments $(70.9 \%$ of claimants, $n=26,444)$ may have recovered compared with claimants who also had claims during the chronic post-injury period. Logistic regression showed that claimants with only acute payments were more likely to be male $(\mathrm{OR}=1.31 ; 95 \% \mathrm{CI}$ : 1.24 to 1.38 ); compared with $18-24$ year olds, significantly less likely to be $45-54$ years $(\mathrm{OR}=0.86$; $95 \% \mathrm{CI}$ : 0.78 to 0.94 ), $55-64$ years ( $\mathrm{OR}=0.79 ; 95 \% \mathrm{CI}: 0.71$ to 0.87 ) and $>65$ years $(\mathrm{OR}=0.74 ; 95 \%$ CI: 0.66 to 0.82$)$; compared to the beginning of the study (2000/2001), were significantly more likely to have an accident in the years $2004 / 2005$ (OR $=1.32$; 95\% CI: 1.20 to 1.45 ), 2006/ $2007(\mathrm{OR}=1.45$ 95\% CI:1.32 to 1.58$), 2008 / 2009$ (OR = 1.32; CI:1.20 to 1.45 ), and $2010 / 2011$ (OR $=1.24 ; 95 \%$ CI: 1.13 to 1.37 ); and significant less likely to have a common law claim $(\mathrm{OR}=0.06$; $95 \% \mathrm{CI}: 0.05$ to 0.07$)$. Although significant, $(\times 2(\mathrm{df}=14)=3443.1, p<.000)$, the model only explained between $8.8 \%$ (Cox \& Snell R2) and $12.6 \%$ (Nagelkerke R2) of the variance.

On the other hand, it was supposed that high service use (e.g. highest quartile, number of health service payments $\geq 10(n=7779))$ may have been associated with greater on-going pain and disability. Logistic regression showed that claimants with highest quartile of health services payments were more likely to be female $(\mathrm{OR}=$ 0.74 ; $95 \%$ CI: 0.70 to 0.78 ); and compared with $18-24$ year olds, significantly more likely to be $45-54$ years $(\mathrm{OR}=1.18$; $95 \% \mathrm{CI}: 1.06$ to 1.31$)$, 55-64 years $(\mathrm{OR}=$ 1.30; $95 \%$ CI: 1.17 to 1.45$)$ and $>65$ years $(\mathrm{OR}=1.41$; 95\% CI: 1.25 to 1.59 ); compared to the beginning of the study $(2000 / 2001)$, were significantly less likely to have an accident in the years $2004 / 2005(\mathrm{OR}=0.84 ; 95 \% \mathrm{CI}$ : 0.76 to 0.93 ), $2006 / 2007$ (OR $=0.74$; CI:0.67 to 0.82 ), 2008/2009 (OR $=0.80$; 95\% CI: 0.72 to 0.89 ), $2010 / 2011$ $(\mathrm{OR}=0.81$; CI:0.73 to 0.90$)$, and $2012 / 2013$ (OR =0.87; 95\% CI: 0.79 to 0.97 ); and significantly more likely to have a common law claim (OR $=7.19 ; 95 \% \mathrm{CI}$ : 6.41 to 8.06). Although significant $(\mathrm{X} 2=2474.36, \mathrm{df}=14$, $p=.000)$, the model only explained between $6.4 \%$ (Cox \& Snell R2) and 10.0\% (Nagelkerke R2) of the variance.

\section{Discussion}

Individuals with WAD claimed for a range of medical and allied health services. The majority of claimants used emergency services initially. During an acute postinjury period, claimants tended to use medical services with similar numbers of claimants consulting with GPs and medical specialists. Individuals with an on-going need for health services expanded their treatment to include more diverse allied health services while continuing to consult with GPs. Clinical management guidelines for WAD address these types of medical and allied health services through recommendations for treatment, and where indicated, referral to radiological imaging and specific medical and health services $[9,10,20,21]$. Our current study findings provide a clearer understanding of guideline concordant and discordant health care utilization during both acute and chronic post-injury periods.

Current clinical management guidelines for acute WAD recommend the Canadian C-Spine rule be applied in alert and stable trauma patients [22] to screen for clinically important cervical spine injuries $[8,10]$. For individuals found to be at risk of a clinically important cervical spine injury, radiological imaging is oftentimes used to establish a diagnosis. For individuals not at risk of clinically important cervical spine injuries, radiological imaging is not recommended and unnecessary radiological imaging is avoided. Of individuals who present to an ED, clinically important cervical spine injuries occur in approximately $2 \%$ of individuals following a blunt trauma (e.g. MVC) $[22,23]$ and in less than $1 \%$ of individuals with an acute whiplash injury [24]. Although it is unknown whether the Canadian C-Spine rule was used in the present study, the apparently high acute postinjury imaging rate of $56 \%$ is similar to Canadian [25] and Australian [26] ED imaging rates where successful implementation of the Canadian C-Spine rule resulted in no missed cervical fractures or dislocations.

Most of the acute radiology payments were for $\mathrm{x}$-rays (91\%), though one in five claimants had a CT scan and annual CT scan imaging rates doubled from the beginning to end of the study period. Emergent evidence has shown that CT scans are significantly more sensitive than $\mathrm{x}$-rays for identifying cervical spine fractures [27], and are now considered the optimal modality for identifying this type of injury despite the higher radiation levels $[28,29]$. The use of $x$-rays and CT scans during a chronic post-injury phase is unclear since identification of a clinically important cervical spine injury would be evident acutely. Over one-third of chronic post-injury radiology claimants had a CT scan, almost half had an $x$-ray, and half of male and $44 \%$ of females had a MRI. MRI may have been used to screen for neurological complications in individuals who were not recovering. 
However, the percentage of individuals with neurological complications in this population is usually very small [24, 30, 31]. Importantly, results from imaging during a chronic post-injury phase do not provide additional information that lead to changes in treatment [32]. Given the need to minimise unnecessary costs, exposure to radiation, and possible psychological stress associated with unnecessary radiological imaging, the high use of radiological imaging during a chronic recovery period in the present study is a concern.

The reasons for radiology imaging in the present study are unknown. Perhaps patients with on-going WAD continue to search for a diagnosis to legitimise their pain, and may request or demand additional testing [33, 34]. Clinicians may not be adequately prepared to explain reasons why imaging may be inappropriate and possibly detrimental [35], or may fear missing a fracture [32]. Promoting discussions and education about unnecessary healthcare as advocated by initiatives such as 'Choosing Wisely ' $[36,37]$ may help both healthcare providers and their patients better understand evidencebased recommendations for tests, treatments and procedures such as radiological imaging.

In Australia, most primary medical care is provided by GPs, the most common medical service provider consulted by individuals with WAD [17, 38]. However, in the present study, slightly more claimants consulted with medical specialists than with GPs during an acute postinjury period. Although reversed during a chronic postinjury period, $35 \%$ of male claimants continued to consult with medical specialists. Furthermore, from the beginning to the end of the study period, the percentage of claim payments for medical specialists increased by $50 \%$ while GP consultations decreased by one-third. Since 1995, the core clinical guideline recommendations for WAD have remained similar: provide reassurance and advice to encourage return to usual activity and exercise; and avoid immobility collars, [8-10, 20, 21, 39], surgery and pharmaceutical injections $[8,9,40]$. Compared with access to medical specialists, significantly fewer claimants accessed health services likely to encourage an active approach to treatment, such as physiotherapy and chiropractic services [41], during the acute post-injury period. Although the specific type of medical speciality and the reasons for referral to a medical specialist are unknown, and provision of advice to encourage return to usual activity and exercise does not need to come from a physiotherapist or chiropractor, the relatively high referral rates to medical specialists were surprising. Further research is needed to investigate the reasons for referral to medical specialists in this population.

Most previous studies have not differentiated physiotherapy or chiropractor usage rates during acute versus chronic post-injury periods for individuals with WAD, though in another Australian state, 50\% received physiotherapy at 9 weeks post-injury [30], and, in Canada, 25\% received physiotherapy and $8 \%$ received chiropractor services within 6 weeks post- injury [12]. Lower usage rates were found in the present study: only $15 \%$ of acute post-injury claimants accessed physiotherapy and $4 \%$ accessed chiropractic services. Perhaps, individuals who visited a physiotherapist or chiropractor did not meet the monetary excess required for a TAC service payment and therefore were not included with our data. Alternatively, claimants may have relied on GPs or medical specialist healthcare in the weeks immediately following their injury. Early access to physiotherapy may help to minimise overall healthcare use and promote self-report recovery [12], though overuse of treatments may lead to treatment dependency [12, 14]. Reduced self-report recovery was reported for individuals who had more than six physiotherapy or chiropractor sessions in the first 6 weeks post- whiplash injury [12]. In our study, the volume of consultations appeared to be appropriate during an acute post-injury period (i.e. median $=6$ sessions in 12 weeks). The optimal number of treatment sessions during a chronic post-injury period is unknown.

The very high number of physiotherapy and chiropractor sessions per claimant (e.g. 20) during the chronic postinjury period in the present study was higher than previously reported in Australia (e.g. 15) [14, 30]. Consistent with previous research, approximately one-third of WAD claimants appeared to have some level of on-going disability indicated by a health service payment during the chronic post-injury period $[2,6]$, two-thirds of claimants were female $[6,42,43]$, and females were more likely than males to have allied health service payments. Evidence clearly show that females are more likely than males to consult with physiotherapists [14, 44, 45], chiropractors [46], and mental health professionals [47, 48]. Possible gender differences in perceptions of health [49] and reporting of symptoms $[45,49]$ may result in females seeking more or different help for prevention or illness [49]. Alternatively, males may feel that allied health services, such as physiotherapy or psychology, are less acceptable types of health management [45].

Psychology services were accessed by $1 \%$ of claimants during an acute post-injury period, and $13 \%$ of females and $10 \%$ of males during a chronic post-injury period. To our knowledge, no previous data are available about referral rates of individuals with WAD to psychologists despite evidence that one-quarter of individuals with chronic WAD have a co-morbid mental health disorder/distress [50], acute stress symptoms are prognostic for poor recovery [51], and over $40 \%$ of chronic post-injury pharmaceutical claimants from the same data cohort received an antidepressant [18]. Current clinical WAD management guidelines recommend assessing for post-traumatic stress 
symptoms where appropriate and onward referral to mental health specialists if required [8]. However, individuals with WAD may be reluctant to consult with psychologists. Individuals with acute WAD questioned the relevance of seeing a psychologist for what they perceived to be a physical injury [52], and individuals with on-going WAD indicated that referral to a psychologist did not align with their treatment expectations [53]. The $40 \%$ increase in the percentage of claimants accessing psychology health services over the study period suggests that perceptions of psychology management may be changing in this population. Further research is needed to better understand how and when to appropriately utilize psychological services to improve treatment outcomes, and patient expectations and understanding of psychological health services.

This study provides much needed data about health service use during acute and chronic post-injury periods in individuals with WAD. Nevertheless, limitations exist. Health service use may have been underestimated for two reasons. Firstly, there may have been individuals injured in an MVC who were entitled to claim, but did not lodge a claim for various reasons (e.g., may have had a minor injury that recovered), and hence were not included in the CRD. Secondly, some individuals entitled to make a TAC claim may have received healthcare, but did not meet the monetary excess for reimbursement, and hence were not included in the CRD. However, the monetary excess was likely met for individuals with chronic WAD. Thus, it is likely that the data for the present study captured chronic health service use. Finally, generalisability may be limited since the data were for individuals injured in a single Australian jurisdiction. Given that all individuals with a whiplash injury from an MVC are eligible to claim for health service costs within the no-fault compensation system in Victoria, it is likely that the data represented a general WAD cohort.

\section{Conclusions}

In conclusion, these health service use data provide a better understanding of healthcare service utilization by individuals with WAD during acute and chronic post-injury periods. Apparent concordance with current clinical WAD management guidelines occurred for radiology imaging usage rates during the acute post-injury period, and for physiotherapy and chiropractor services during a chronic post-injury period. Conversely, the low physiotherapy and chiropractic usage during an acute postinjury period, and high referral rates to radiology imaging and medical specialists during the chronic post-injury period appeared discordant with current clinical management guidelines. Strategies are needed to help inform medical health professionals of the current clinical WAD management guidelines to promote early access to health professionals likely to provide an active approach to treatment, and to reduce unnecessary referral to radiology and medical specialists in individuals with on-going WAD.

\section{Abbreviations \\ AU: Australian; CRD: Compensation Research Database; C-Spine: Canadian Cervical Spine rule; CT: Computed tomography; GP: General practitioner; MRI: Magnetic resonance imaging; MVC: Motor vehicle crash; \\ OT: Occupational therapist; QTF: Quebec Task Force; TAC: Transport Accident \\ Commission; WAD: Whiplash associated disorder}

\section{Acknowledgements}

This paper uses unit record data from the Compensation Research Database (CRD). The CRD was initiated and funded by the Transport Accident Commission (TAC), Worksafe Victoria (WSV) and Monash University and is managed by the Institute for Safety, Compensation and Recovery Research (ISCRR). The findings and views reported in this paper, however, are those of the author/s and should not be attributed to TAC, WSV, or ISCRR.

\section{Authors' contributions}

CR, AS and MS all contributed to the conception and design of the study, interpretation of the data, and writing the manuscript. CR managed and analysed the data. All authors read and approved the final manuscript.

\section{Funding}

No external funding was received for this project.

\section{Availability of data and materials}

Data to support the findings of this study are available from the Institute for Safety, Compensation and Recovery Research (https://www.iscrr.com.au/), however restrictions apply to the availability of these data, which were used under contract for the current study, and so are not publicly available.

\section{Ethics approval and consent to participate}

The research was performed in accordance with the Declaration of Helsinki. Permission to use the de-identified data for this study was provided by the Institute for Safety, Compensation and Recovery Research (ISCRR), Victoria, Australia. Human research ethics approval was granted from The University of Queensland, Australia (\#2017001361/2016/112).

\section{Consent for publication}

Not applicable.

\section{Competing interests}

The authors declare that they have no competing interests.

\section{Author details}

${ }^{1}$ Recover Injury Research Centre, The University of Queensland, Brisbane, Queensland, Australia. ${ }^{2}$ School of Allied Health Sciences, Griffith University, Gold Coast, Australia. ${ }^{3}$ Department of Clinical Neurosciences, Cumming School of Medicine, University of Calgary, Calgary, Canada. ${ }^{4} \mathrm{NHMRC}$ Centre of Research Excellence in Road Traffic Injury Recovery, Brisbane, Australia.

Received: 1 December 2019 Accepted: 24 March 2020

Published online: 30 March 2020

References

1. Connelly LB, Supangan R. The economic costs of road traffic crashes: Australia, states and territories. Accid Anal Prev. 2006;38(6):1087-93.

2. Sterling M, Hendrikz J, Kenardy J. Compensation claim lodgement and health outcome developmental trajectories following whiplash injury: a prospective study. Pain. 2010;150(1):22-8.

3. Carroll L, Holm L, Hogg-Johnston S. Course and prognostic factors for neck pain in whiplash associated disorder (WAD): results of the bone and joint decade 2000-2010 task force on neck pain and its associated disorders. J Manipulative Physiol Ther Suppl. 2009;32(2):S97-107.

4. Sterling M. Physiotherapy management of whiplash-associated disorders (WAD). J Phys. 2014;60(1):5-12.

5. Teasell RW, McClure JA, Walton D, Pretty J, Salter K, Meyer M, et al. A research synthesis of therapeutic interventions for whiplash-associated disorder: part 1 overview and summary. Pain Res Manag. 2010;15(5):287-94. 
6. Kamper SJ, Rebbeck T, Maher CG, McAuley JH, Sterling M. Course and prognostic factors of whiplash: a systematic review and meta-analysis. Pain. 2008;138:617-29.

7. Spitzer W, Skovron M, Salmi L, Cassidy JD, Duranceau J, Suissa S, et al. Scientific monograph of Quebec task force on whiplash associated disorders: redefining "whiplash" and its management. Spine. 1995;20(8S):1-73.

8. State Insurance Regulatory Authority. Guidelines for the management of acute whiplash-associated disorders - for health professionals. Sydney: State Insurance Regulatory Authority (SIRA); 2014.

9. South Australian Centre for Trauma and Injury Recovery (TRACsa). Clinial guidelines for best practice management of acute and chronic whiplash associated disorders: clinical resource guide. South Australia; 2008.

10. Côté P, Wong JJ, Sutton D, Shearer HM, Mior S, Randhawa K, et al. Management of neck pain and associated disorders: a clinical practice guideline from the Ontario protocol for traffic injury management (OPTIMa) collaboration. Eur Spine J. 2016;25(7):2000-22.

11. Horn ME, Fritz JM. Timing of physical therapy consultation on 1-year healthcare utilization and costs in patients seeking care for neck pain: a retrospective cohort. BMC Health Serv Res. 2018;18(1):887.

12. Skillgate E, Côté $P$, Cassidy JD, Boyle E, Carroll L, Holm LW. Effect of early intensive care on recovery from whiplash-associated disorders: results of a population-based cohort study. Arch Phys Med Rehabil. 2016;97(5):739-46.

13. Côté P, Hogg-Johnson S, Cassidy JD, Carroll L, Frank JW, Bombardier C. Early aggressive care and delayed recovery from whiplash: isolated finding or reproducible result? Arthritis Care Res. 2007:57(5):861-8.

14. Grimmer-Somers K, Milanese S, Kumar S, Brennan C, Mifsud I. Number and frequency of physiotherapy services for motor vehicle-induced whiplash: interrogating motor acident insurance data 2006-2009. J Rehabil Med. 2012; 44(9):774-80.

15. Lamb SE, Williams MA, Withers E, Perry J, Gates S, Williamson E, et al. A national survey of clinical practice for the management of whiplash-associated disorders in UK emergency departments. Emerg Med J. 2009;26:644-7.

16. Brijnath B, Bunzli S, Xia T, Singh N, Schattner P, Collie A, et al. General practitioners knowledge and management of whiplash associated disorders and post-traumatic stress disorder: implications for patient care. BMC Fam Pract. 2016;17:82.

17. Nikles J, Yelland M, Bayram C, Miller G, Sterling M. Management of Whiplash Associated Disorders in Australian general practice. BMC Musculoskelet Disord. 2017;18(1):551.

18. Ritchie C, Hollingworth SA, Warren J, Sterling M. Medicine use during acute and chronic postinjury periods in whiplash-injured individuals. Pain. 2019; 160(4):844-51.

19. Australian Bureau of Statistics. Australian Statistical Geography Standard (ASGS). 2016.

20. Motor Accident Authority. Guidelines for the Management of WhiplashAssociated Disorders. Sydney: Motor Accident Authority (MAA); 2001.

21. Motor Accident Authority. Guidelines for the management of whiplash associated disorders. Sydney: Motor Accident Authority (MAA); 2007.

22. Stiell IG, Wells GA, Vandemheen KL, Clement CM, Lesiuk H, De Maio VJ, et al. The Canadian C-spine rule for radiography in alert and stable trauma patients. JAMA. 2001;286(15):1841-8.

23. Goldberg W, Mueller C, Panacek E, Tigges S, Hoffman JR, Mower WR. Distribution and patterns of blunt traumatic cervical spine injury. Ann Emerg Med. 2001;38(1):17-21.

24. Miettinen T, Lindgren K-A, Airaksinen O, Leino E. Whiplash injuries in Finland: a prospective 1-year follow-up study. Clin Exp Rheumatol. 2002;20(3):399-402.

25. Stiell IG, Clement CM, Grimshaw J, Brison RJ, Rowe BH, Schull MJ, et al. Implementation of the Canadian C-Spine Rule: prospective 12 centre cluster randomised trial. BMJ. 2009;339:b4146.

26. Kerr D, Bradshaw L, Kelly A-M. Implementation of the Canadian C-spine rule reduces cervical spine $x$-ray rate for alert patients with potential neck injury. J Emerg Med. 2005;28(2):127-31.

27. Bailitz J, Starr F, Beecroft M, Bankoff J, Roberts R, Bokhari F, et al. CT should replace three-view radiographs as the initial screening test in patients at high, moderate, and low risk for blunt cervical spine injury: a prospective comparison. J Trauma. 2009;66(6):1605-9.

28. American College of Radiology. ACR Appropriateness Criteria Suspected Spine Tramua 2019 [Available from: https:/acsearch.acr.org/docs/69359/Narrative/.

29. Goergen S, Varma D, Ackland H, Michaleff Z, Rosenfeld J, Malham G, et al. Adult Cervical Spine Trauma. Sydney: The Royal Australian and New Zealand College of Radiologists; 2015.
30. Bandong AN, Leaver A, Mackey M, Ingram R, Shearman S, Chan C, et al. Adoption and use of guidelines for whiplash: an audit of insurer and health professional practice in New South Wales, Australia. BMC Health Serv Res. 2018;18(1):622.

31. Pajediene E, Janusauskaite J, Samusyte G, Stasaitis K, Petrikonis K, Bileviciute-Ljungar I. Patterns of acute whiplash-associated disorder in the Lithuanian population after road traffic accidents. J Rehabil Med. 2015;47(1):52-7.

32. Michaleff Z, Maher CG, Verhagen AP, Rebbeck T, Lin C. Accuracy of the Canadian C-spine rule and NEXUS to screen for clinically important cervical spine injury in patients following blunt trauma: a systematic review. Can Med Assoc J. 2012;184(16):E867-E76.

33. Keating JL, McKenzie JE, O'Connor DA, French S, Walker BF, Charity M, et al. Providing services for acute low-back pain: a survey of Australian physiotherapists. Man Ther. 2016;22:145-52.

34. Chou L, Ranger TA, Peiris W, Cicuttini FM, Urquhart DM, Sullivan K, et al. Patients' perceived needs for medical services for non-specific low back pain: a systematic scoping review. PLoS One. 2018;13(11):e0204885.

35. Courtney DM. Assessment and management of whiplash from the emergency and acute care setting: care, questions, and future global research needs. J Orthop Sports Phys Ther. 2016;46(10):822-5.

36. Choosing Wisely. Choosing Wisely Australia: NPS Medicine Wise; 2015 [Available from: http://www.choosingwisely.org.au/home.

37. Choosing Wisely. Choosing Wisely: An initiative of the ABIM Foundation 2012 [Available from: https://www.choosingwisely.org/.

38. Rebbeck T, Macedo L, Paul P, Trevena L, Cameron ID. General practitioners' knowledge of whiplash guidelines improved with online education. Aust Health Rev. 2013;37(5):688-94.

39. Blanpied PR, Gross AR, Elliott JM, Devaney LL, Clewley D, Walton DM, et al. Neck pain: revision 2017. J Orthop Sports Phys Ther. 2017;47(7):A1-A83.

40. Wong JJ, Côté P, Shearer HM, Carroll L, Yu H, Varatharajan S, et al. Clinical practice guidelines for the management of conditions related to traffic collisions: a systematic review by the OPTIMa Collaboration. Informa Healthcare. 2015;37(6):471-89.

41. Carlesso LC, MacDermid JC, Gross AR, Walton DM, Santaguida PL. Treatment preferences amongst physical therapists and chiropractors for the management of neck pain: results of an international survey. Chiropr Man Therap. 2014;22(1):11.

42. Hendriks EJM, Scholten-Peeters GGM, Van Der Windt DAWM, Neeleman-Van Der Steen CWM, Oostendorp RAB, Verhagen AP. Prognostic factors for poor recovery in acute whiplash patients. Pain. 2005;114(3):408-16.

43. Walton DM, MacDermid JC, Giorgianni AA, Mascarenhas JC, West SC, Zammit CA. Risk factors for persistent problems following acute whiplash injury: update of a systematic review and meta-analysis. J Orthop Sports Phys Ther. 2013;43(2):31-43.

44. Freburg JK, Carey TS, Holmes GM. Management of back and neck pain: who care from physical therapists? Phys Ther. 2005;85(9):872-86.

45. Chevan J, Riddle DL. Factors associated with care seeking from physicians, physical therapists, or chiropractors by persons with spinal pain: a population-based study. J Orthop Sports Phys Ther. 2011;41(7):467-76.

46. Beliveau PJH, Wong JJ, Sutton DA, Simon NB, Bussières AE, Mior SA, et al. The chiropractic profession: a scoping review of utilization rates, reasons for seeking care, patient profiles, and care provided. Chiropr Man Therap. 2017;25(1):35.

47. Thompson AE, Anisimowicz Y, Miedema B, Hogg W, Wodchis WP, Aubrey-Bassler $K$. The influence of gender and other patient characteristics on health careseeking behaviour: a QUALICOPC study.(Report). BMC Fam Pract. 2016;17(38):38.

48. Australian Bureau of Statistics. National health survey: health service usage and health related actions, Australia, 2014-2015. Canberra: Australian Bureau of Statistics; 2017.

49. Bertakis K, Azari R, Callahan E, Robbins J. Gender differences in the utilization of health care services. J Fam Pract. 2000;49(2):147-52.

50. Landén Ludvigsson M, Peterson G, Peolsson A. The effect of three exercise approaches on health-related quality of life, and factors associated with its improvement in chronic whiplash-associated disorders: analysis of a randomized controlled trial. Qual Life Res. 2019;28:357-68.

51. Campbell L, Smith A, McGregor L, Sterling M. Psychological factors and the development of chronic whiplash associated disorder(s): a systematic review. Clin J Pain. 2018;34(8):755-68.

52. Jull G, Kenardy J, Hendrikz J, Cohen M, Sterling M. Management of acute whiplash: a randomized controlled trial of multidisciplinary stratified treatments. Pain. 2013;154(9):1798-806. 
53. Ritchie C, Ehrlich C, Sterling M. Living with ongoing whiplash associated disorders: a qualitative study of individual perceptions and experiences. BMC Musculoskeletal Disord. 2017;18(1):531.

\section{Publisher's Note}

Springer Nature remains neutral with regard to jurisdictional claims in published maps and institutional affiliations.

- fast, convenient online submission

- thorough peer review by experienced researchers in your field

- rapid publication on acceptance

- support for research data, including large and complex data types

- gold Open Access which fosters wider collaboration and increased citations

- maximum visibility for your research: over $100 \mathrm{M}$ website views per year

At BMC, research is always in progress. 